\title{
The DLR Project LamAiR: Design of a NLF Forward Swept Wing for Short and Medium Range Transport Application
}

\author{
Arne Seitz ${ }^{1}$, Martin Kruse ${ }^{2}$ and Tobias Wunderlich ${ }^{3}$ \\ DLR, Institute of Aerodynamics and Flow Technology, 38108, Braunschweig, Germany \\ and \\ Jens Bold ${ }^{4}$ and Lars Heinrich ${ }^{5}$ \\ DLR, Institute of Composite Structures, 38108, Braunschweig, Germany
}

\begin{abstract}
The LamAiR (Laminar Aircraft Research) project deals with the design of a laminar wing for short and medium range transport aircraft operated in the transonic regime. It is well known that extensive laminar flow on wings of such aircraft still can be achieved by natural means, i.e. solely by contour shaping of the airfoil sections. But with Reynolds numbers being in the order of 25 millions in cruise condition the leading edge sweep of the wing should not be higher than approximately $20 \mathrm{deg}$ in order to limit the growth of crossflow instabilities and, hence, prevent early transition. Consequently, the design cruise Mach number for laminar wings of conventionally aft-swept configurations cannot exceed values of about 0.75 and it is expected that the high-speed off-design performance is rather poor. Within the DLR project LamAiR it is therefore investigated if these aerodynamic shortcomings can be overcome by employing forward sweep in combination with aeroelastic tailoring using CFRP (Carbon Fiber Reinforced Plastics) materials. In particular the goal is to design a forward swept laminar wing having a design Mach number of 0.78 and the capability of reaching Mach 0.80 in high-speed off-design. The present paper gives an overview on the current status of the project as well as prospects for future work.
\end{abstract}

\section{Nomenclature}

$\begin{array}{ll}\text { ALT } & =\text { attachment line transition } \\ \mathrm{C}_{\mathrm{L}} & =\text { lift coefficient } \\ \mathrm{CFI} & =\text { crossflow instability } \\ \mathrm{CFRP} & =\text { carbon fiber reinforced plastics } \\ \mathrm{C}_{\mathrm{P}}, \mathrm{C}_{\mathrm{P}}{ }^{*} & =\text { pressure coefficient and critical pressure coefficient } \\ \mathrm{C} & =\text { chord length } \\ \mathrm{C}_{1} & =\text { section or local lift coefficient } \\ \mathrm{C}_{\mathrm{df}} & =\text { section friction drag coefficient } \\ \mathrm{C}_{\mathrm{dw}} & =\text { section wave drag coefficient } \\ \mathrm{C}_{\mathrm{m} 25} & =\text { pitching moment about quarter chord point } \\ \mathrm{dc} & =\text { drag counts } \\ \mathrm{NLF} & =\text { natural laminar flow } \\ \mathrm{N}_{\mathrm{CF}} & =\text { crossflow N-factor } \\ \mathrm{N}_{\mathrm{CF}} & =\text { crossflow N-factor } \\ \mathrm{M} & =\text { Mach number } \\ \mathrm{Re}_{\mathrm{AMC}} & =\text { Reynolds number based on aerodynamic mean chord } \\ \end{array}$

\footnotetext{
${ }^{1}$ Research Scientist, DLR Braunschweig, Lilienthalplatz 7, 38108 Braunschweig, arne.seitz@dlr.de.

${ }^{2}$ Research Scientist, DLR Braunschweig, Lilienthalplatz 7, 38108 Braunschweig, martin.kruse@dlr.de.

${ }^{3}$ Research Scientist, DLR Braunschweig, Lilienthalplatz 7, 38108 Braunschweig, tobias.wunderlich@dlr.de.

${ }^{4}$ Research Scientist, DLR Braunschweig, Lilienthalplatz 7, 38108 Braunschweig, jens.bold@dlr.de.

${ }^{5}$ Research Scientist, DLR Braunschweig, Lilienthalplatz 7, 38108 Braunschweig, lars.heinrich@dlr.de.
} 